\title{
THE STUDY ON THE DURABILITY OF SUBMERGED STRUCTURE DISPLACEMENT DUE TO CONCRETE FAILURE
}

\author{
M. Mohd ${ }^{\mathrm{a}}$, O. Zainon ${ }^{\mathrm{b}}$, A. W. Rasib ${ }^{\mathrm{b}}, \mathrm{Z}_{\text {Majid }}^{\mathrm{b}}$ \\ ${ }^{a}$ Department of Civil Engineering, Politeknik Ungku Omar, Jalan Raja Musa Mahadi, 31400 Ipoh, Perak. \\ masbasri@puo.edu.my \\ ${ }^{\mathrm{b}}$ Department of Geoinformation, Faculty of Geoinformation and Real Estate, Universiti Teknologi Malaysia, \\ 81310 Johor Bahru. Johor. othmanz.kl@utm.my, abdwahid@utm.my, zulkeplimajid@utm.my
}

KEY WORDS: Durability, Submerged Structure, Displacement, Concrete Failure

\begin{abstract}
Concrete structures that exposed to marine environments are subjected to multiple deterioration mechanisms. An overview of the existing technology for submerged concrete, pressure resistant, concrete structures which related such as cracks, debonds, and delamination are discussed. Basic knowledge related to drowning durability such as submerged concrete structures in the maritime environment are the durability of a concrete and the ability to resist to weathering, chemical attack, abrasion or other deterioration processes. The measuring techniques and instrumentation for geometrical monitoring of submerged structural displacements have traditionally been categorized into two groups according to the two main groups, namely as geodetic surveying and geotechnical structural measurements of local displacements. This paper aims to study the durability of submerged concrete displacement and harmful effects of submerged concrete structures.
\end{abstract}

\section{INTRODUCTION}

As the new materials and technologies are increasingly applied to construction of civil infrastructures such bridges, dam and tunnels, the need for structural monitoring systems, maintenance and restoration becomes more important and vital. Bridges are widespread in every society and affect its human, social, economical and cultural aspects. Beshr (2015) stated that the measurements and monitoring of the structural displacement of highway bridges have an essential role in structural safety.

Reinforced concrete bridge systems are designed with the objective of keeping inelastic displacements within the columns and away from the superstructure. For this reason accurate representation of the behavior of bridge columns in the inelastic range of response is important for the development of computer models that evaluate the performance of bridge systems under earthquake events. Understanding the spread of inelastic displacements at various stages of loading is also important to quantify the expected progression of damage and to estimate the displacement at which loss of lateral load capacity takes place. This is a particularly difficult problem when the structure is subjected to multiaxial loading, or when the structural components have a complex geometric shape (Browning, 2011).

Making long term durable concrete structures in a marine environment is a common concern to concrete professionals. Generally, marine structures are damaged by the chloride induced corrosion of steel bars in concrete. According to Mohammed, Hamada, and Yamaji (2003) the deterioration of microstructures of concrete due to the reaction of hydration products of cement and seawater, mainly dissolved $\mathrm{CO} 2$ in seawater and magnesium salts, such as $\mathrm{MgCl} 2$ and $\mathrm{MgSO} 4$.

\section{SUBMERGED CONCRETE STRUCTURE (SCS)}

Concrete consists of a mixture of sand, gravel, crushed stone or other aggregate bound together with a hard paste hydraulic cement and water. These materials form a mass that can be placed into the form of the desired size and form. Submerged concrete which poured underwater must have good workability. Therefore, it should meet several conditions, such as (Naval Facilities Engineering Command, 1995):

1) The mixture must incorporate the proper proportions of sand and gravel (preferably not crushed material) in a rich paste of port land cement and freshwater.

2) The mixing water must not exceed 5.5 gallons per bag of cement. (Mixing water includes the water entering the batch in the form of free, surface moisture on the sand and/or gravel; this free water must, therefore, be deducted from the total water to be added.) If the aggregate particles are surface-dry and not saturated, they will absorb some of the gross mixing water; allowance must, therefore, be made for extra mixing water, taking care that the $\mathrm{W} / \mathrm{C}$ ratio of 5.5 gallons per bag is not exceeded.

3) The mixture should not contain less than 8 bags and not more than 10 bags of cement per cubic yard of ASTM Type V concrete.

4) The concrete should incorporate an admixture to provide not less than 3\% and not more than 6\% entrained air as determined by standard ASTM methods.

5) The sand and gravel should be physically sound, and the maximum gravel size should be $3 / 4$ inch singlespaced, unless otherwise stated. Left and right justified typing is preferred.

6) The formwork in which the concrete is poured must be rigid, carefully fitted, and designed so that no underwater currents can pass through it. Provision must be made for the seawater displaced by the concrete to escape from within the form. Timber is 
generally the most suitable material for construction of the formwork. Joints between the formwork and the intact portion of a structure should be caulked.

7) Low temperatures during mixing and curing of concrete (i.e., below $50^{\circ} \mathrm{F}$ ) can delay strength development for periods as long as one year and so should be avoided.

8) An enclosed chute or "trunk" should be specified so that there is no mixing with water during placement.

However, submerged concrete structures exposed to marine environments which are subjected to multiple deterioration mechanisms. The reinforcing steel, aggregate, and paste all have the potential for degradation under the environmental conditions present. Figure 1 shows the typical degradation mechanisms that occur in marine environments.

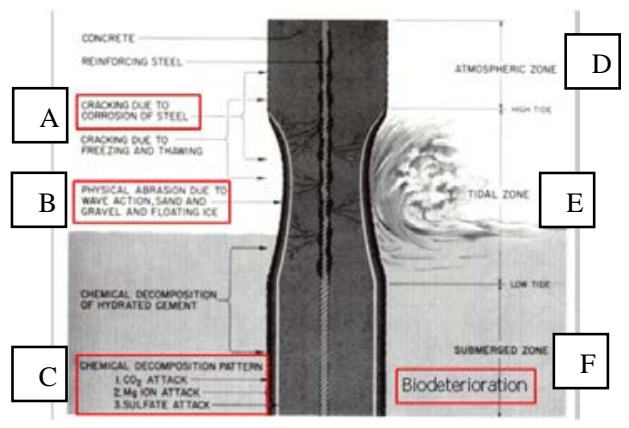

A. Cracking Due To Corrosion Of Steel.

B. Physical Abrasion Due To Wave Action, Sand and Gravel and Floating Ice.

C. Chemical Decomposition Pattern,

1. CO2 Attack

2. Mg Ion Attack

3. Sulfate Attack

D. Atmospheric Zone.

E. Tidal Zone.

F. Submerge Zone.

Figure 1. Typical degradation mechanisms in coastal concrete piling. (Source: Holland, 2012).

\section{DURABILITY OF SCS}

Submerged concrete can be exposed to a wide range of conditions such as the sea water, de-icing salts, stored chemicals or the atmosphere. According to Bill, John and Ray (2012), durability requirements with related design calculations to check the control crack width and depths.

Polder and De Rooji (2005) state that durability of concrete structures in marine environment has been an issue for many decades, due to the perception of sea water as aggressive to concrete and reinforcement and the long service life that is expected for marine infrastructure such as harbor and coastal defense structures. The durability of the submerged concrete is influenced by (Bill, John and Ray, 2012):

i. The exposure conditions;

ii. The cement types;

iii. The concrete quality;

iv. The cover to the reinforcement;

v. The width of any cracks.
These processes lead to the decomposition of hydrated compounds of cement paste and or cracks. Figure 2 shows the durability of a concrete and the ability to resist to weathering, chemical attack, abrasion or other deterioration processes. In many industrialized countries the infrastructure, like bridges and buildings, is fully build. Nevertheless the shift in performance requirements, together with a constant degradation of this infrastructure, leads to the possibility of strengthening or repairing as a more sustainable alternative to demolishing and rebuilding.

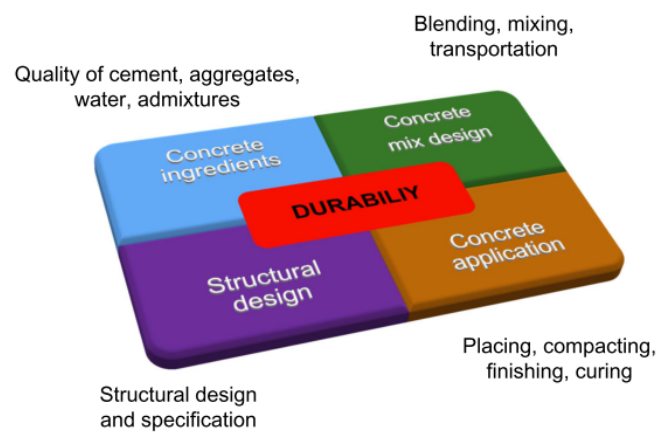

Figure 2. Durability of a concrete and the ability to resist to deterioration processes (Source: (Romer, 2013)

Crack formation in concrete is often at the origin of serious damage due to corrosion. Concrete are massive structures with high economical and social relevance. Among the problems that might affect the service life of the structure are expansive reactions. The expansions may generate internal stresses, cracking and non-recoverable displacements, altering the behavior of the structure and compromising its durability as shown in Figure 3.

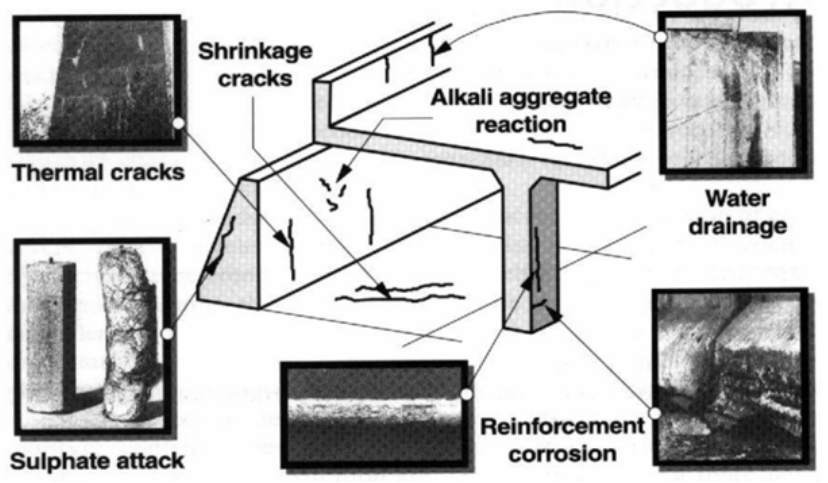

Figure 3. Deterioration in Concrete Structures. (Source: (Song, 2005)

\section{THE DAMAGE OCCUR DUE TO CONCRETE FAILURE}

Furthermore, certain phenomena occurring in the submerged concrete cannot be detected through monitoring or visual inspection; instead numerical analyses are required in order to confirm their existence.

Damages in the material lead to nonlinear behavior. For instance, whenever two pieces of paper stapled together, the metal staples are permanently bent into a different shape. If heavily load a wooden shelf, it will sag more and more as time passes. As weight is added to a car or truck, the contact surfaces 
between its pneumatic tires and the underlying pavement change in response to the added load. If you were to plot the load-deflection curve for each of these examples, you would discover that they all exhibit the fundamental characteristic of nonlinear structural behavior a changing structural stiffness.

Avadutala (2005) state that non-linear structural behavior arises from a number of causes such as Geometric nonlinearities. Geometric nonlinearities are a structure experiences large displacements, its changing geometric configuration can cause the structure to respond nonlinearly. Geometric nonlinearity is characterized by "large" displacements and rotations.

\subsection{Cracks}

Cracks and flaws occur in many structures and components, sometimes leading to disastrous results. The engineering field of fracture mechanics was established to develop a basic understanding of such crack propagation problems (Avadutala, 2005). A crack is a type of fracture that separates a solid body into two, or more, pieces under the action of stress. According to Tada, Paris and Irwin (2000) failure can be divided into three types of modes - see Figure 4.

Mode I: The forces are perpendicular to the crack (the crack is horizontal and the forces are vertical), pulling the crack open. This is referred to as the opening mode.

Mode II: The forces are parallel to the crack. One force is pushing the top half of the crack back and the other is pulling the bottom half of the crack forward, both along the same line. This creates a shear crack: the crack is sliding along itself. It is called in-plane shear because the forces are not causing the material to move out of its original plane.

Mode III: The forces are perpendicular to the crack (the crack is in front- back direction, the forces are pulling left and right). This causes the material to separate and slide along itself, moving out of its original plane (which is why it's called out-of-plane shear).

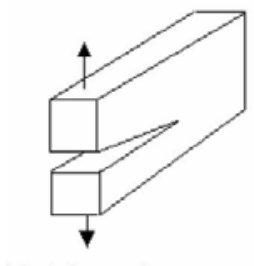

Mode I: opening

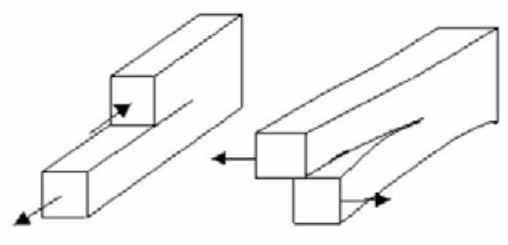

Mode III: out-of-plane shear
Figure 4. Three loading modes (Avadutala, 2005).

Nevertheless, the location of the crack must be known prior to the simulation. In the particular case of concrete such as dams, weak planes may be previously known given the construction process or due to past experience (e.g. construction joints, etc.). These weak planes are preferential pathways for the development of cracks.

\subsection{Debonds}

According to Avadutala (2005), debonds are type of fractures where the bonding between the material molecules are vulnerable to breakage. These occur in weak strength materials more often. These are due to mould defects during manufacturing.

\subsection{Delaminations}

One of the most commonly observed failure modes in composite materials is delamination, a separation of the fiber reinforced layers that are stacked together to form laminates. The most common sources of delamination are the material and structural discontinuities shown in Figure 5. Delamination occur at stress free edges due to the mismatch in properties of the individual layers, at ply drops where thickness must be reduced, and at regions subjected to out-of-plane loading such as bending of curved beams. (Avadutala, 2005).

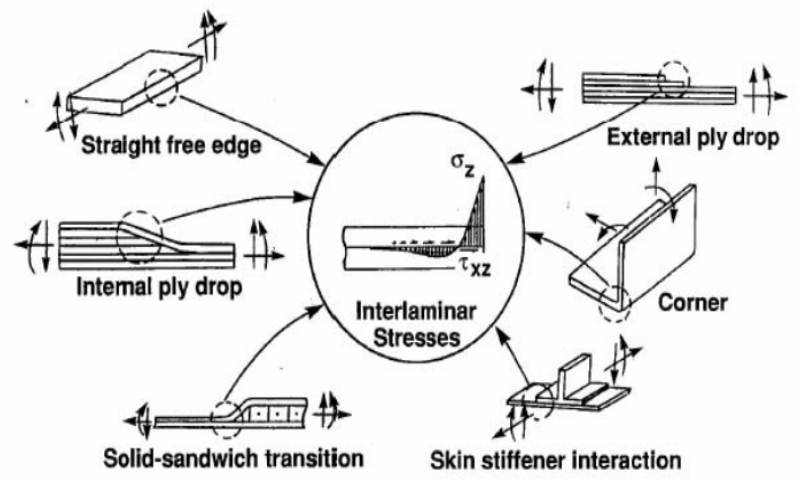

Figure 5. Different types of Delamination (Source: (Avadutala, 2005)

\section{DIPLACEMENT DETECTION INSTRUMENTS}

Nowadays the technology can have a single system to provide wind, earthquake and ambient data for a bridge or other civil structures. Many of the instrumentation is available for highresolution sensing of dynamic input and response parameters, high-resolution data recording and real-time, wireless, remote monitoring of data and derived information (Live, Southern, \& Lobster, 2001). Table 1 show the lists of equipment which relates to sensors for bridge or dam monitoring and displacements on Table 2 as well.

\begin{tabular}{|l|ll|}
\hline $\begin{array}{c}\text { Sensors for } \\
\text { bridge/dam } \\
\text { monitoring }\end{array}$ & - & Accelerometers \\
& - & Strain gages \\
& - & Displacement sensors \\
& - & Wilt meters/tilt sensors \\
& & sensors \\
& - & Temperature sensors \\
& - & Piezometers \\
& - Traffic sensors \\
& - & SMART SENSORS \\
\hline
\end{tabular}

Table 1. Sensors for bridge/dam monitoring (Live et al., 2001).

\begin{tabular}{|l|cl|}
\hline Old tech: & $\bullet$ & LTV \\
& $\bullet$ & String potentiometer \\
\hline New tech: & $\bullet$ & Noncontact (ultrasonic and \\
& & optical) \\
& $\bullet$ & Fiber optic \\
& $\bullet$ & $\begin{array}{l}\text { GPS for static and slow } \\
\text { dynamic }\end{array}$ \\
\hline
\end{tabular}

Table 2: Displacement monitoring techniques

(Live et al., 2001).

The measuring techniques and instrumentation for geometrical monitoring of submerge structural displacements have 
traditionally been categorized into two groups according to the two main groups, namely:

1) Geodetic surveying,

2) Geotechnical structural measurements of local displacements.

According to (Beshr, 2015), each type of the measurements has its own advantages and drawbacks. The acceleration integration method integrates the acceleration, which is measured by acceleration gauge, to obtain the displacement. But its error is relatively large.

Generally in displacement detection studies, three models have been used such as static, kinematic and dynamic models. Static model that is not dependent on time provides the determination of deformations on the characteristic points of the area or the structure, which is monitored. Kinematic models allow estimating the velocity and even the acceleration (by building double differences) of monitoring point movements. The intention of kinematic models is to find a suitable description of point movements by time functions without regarding the potential relationship to causative forces (Beshr, 2015). (Ehigiator, 2013) state in the following Table 3, the three categories of deformation models are characterized by their capacity of taking the factors 'time' and 'load' into account.

\begin{tabular}{|c|c|c|c|}
\hline $\begin{array}{c}\text { Deformation } \\
\text { Model }\end{array}$ & Static Model & $\begin{array}{c}\begin{array}{c}\text { Kinematic } \\
\text { Model }\end{array} \\
\end{array}$ & $\begin{array}{c}\text { Dynamic } \\
\text { Model }\end{array}$ \\
\hline Time & $\begin{array}{l}\text { No } \\
\text { modelling }\end{array}$ & $\begin{array}{l}\text { Movement } \\
\text { as a function } \\
\text { of time }\end{array}$ & \multirow{2}{*}{$\begin{array}{l}\text { Movement } \\
\text { as a } \\
\text { function of } \\
\text { time and } \\
\text { loads }\end{array}$} \\
\hline $\begin{array}{l}\text { Acting } \\
\text { Forces }\end{array}$ & $\begin{array}{l}\text { Displacement } \\
\text { as a function } \\
\text { of load }\end{array}$ & No model & \\
\hline $\begin{array}{l}\text { State of the } \\
\text { object }\end{array}$ & $\begin{array}{l}\text { Sufficiently } \\
\text { in } \\
\text { equilibrium } \\
\text { under loads }\end{array}$ & $\begin{array}{l}\text { Permanently } \\
\text { in motion }\end{array}$ & $\begin{array}{l}\text { Permanently } \\
\text { in motion }\end{array}$ \\
\hline
\end{tabular}

Table 3: Characterization and classification of deformation models (Source: (Ehigiator, 2013).

As one of the latest surveying technologies, it has been proven that GPS to be a useful tool for precision displacement detection applications, in both physical geodesy, and more recently for structural engineering. For continuous structural displacement detection (on an epoch-by-epoch basis) it is desirable for the measurement system to deliver equal precision in all position components, all of the time. However, the qualities of GPS position solutions are heavily dependent on the number and geometric distribution of the available satellites. Therefore, the positioning precision is not the same in all three components, and during a 24-hour period the positioning precision varies significantly. This situation becomes worse when the line-ofsight to GPS satellites is obstructed due to trees or buildings in urban environments, reducing the number of visible satellites (often to less than 4) as stated by (Barnes et al., 2004).

The Global Positioning System (GPS) has been widely used for measuring crustal motion, surface subsidence and ground deformation due to volcanic activity, etc., and more recently for monitoring the deformation of manmade structures such as bridges, dams and buildings (Barnes et al., 2004).

In many of these applications position solutions are required on a continuous basis, at least once a second. In the case of monitoring bridges, this allows early detection of changes in the bridge's response to traffic load, temperature and wind load.
The applied data for analyzing the displacement of any structure from geodetic observations are the coordinates of several monitoring points distributed on the structure itself. The coordinates of these points are calculated with respect to control fixed points. So any deviations in the control points coordinates between the two successive epochs of observations will affect the values of structural displacement. According to (Beshr, 2015), point displacements $\Delta \mathrm{J}$ are calculated by differencing the adjusted coordinates of this point $\mathrm{J}$ for the most recent survey campaign $(\mathrm{k})$, from the coordinates obtained at initial time as follows:

$$
\Delta_{J}=\left[\begin{array}{c}
X_{J}^{K}-X_{J}^{0} \\
Y_{J}^{K}-Y_{J}^{0} \\
Z_{J}^{K}-Z_{J}^{0}
\end{array}\right]=\left[\begin{array}{l}
\Delta X_{J} \\
\Delta Y_{J} \\
\Delta Z_{J}
\end{array}\right]
$$

Where;

$X_{J}^{K}{ }_{x} Y_{J}^{K}{ }_{x} Z_{J}^{K}=$ the adjusted coordinates of monitoring point $\mathrm{J}$ at time $t_{i}^{g}$

$X_{J}^{0}{ }_{J}^{0} Y_{J} Z_{J}^{0}=$ the adjusted coordinates of monitoring point $\mathrm{J}$ at first time observations (initial epoch);

$K=1_{x} 2_{x a x x} m$ ( $m=$ number of observations epochs);

$I=1_{x} 2_{x \ldots x} n$ ( $n=$ number of monitoring points on the bridge).

Geotechnical methods are used extensively in the detection monitoring of structures. During the monitoring, geotechnical sensors of the desired type are carefully chosen and placed at strategic locations to ensure that adequate information is provided to verify design parameters, evaluate the performance of new technologies used in construction, verify and control the construction process and for subsequent deformation monitoring (Othman, 2011).

Geotechnical sensors can either store the measured data internally awaiting download, or the measurements can be automatically logged to a connected computer. Connection to a computer offers a number of advantages (e.g. data stored at a remote location; ability to change update rate of measurement data, when changes in measured values are detected; no need to visit site to download data) and disadvantages (e.g. transfer media required between sensor and computer, for example cable/radio/GSM; loss of data possible if transfer media is not operating and internal storage is not activated). According to Othman (2011), geotechnical sensors provide measurements that are often essential in deformation monitoring. An additional sensor category that completes the portfolio of deformation monitoring sensors, that provide their own analyzable measurements or measurements to calibrate additional sensors, is meteorological sensors.

(Burchfield \& Venkatesan, 2007), abnormal movement detection is facilitated by an analog accelerometer, which is a sensor that varies an output voltage with a direct correlation to the magnitude of acceleration in a given direction. Since a change in acceleration is inherent to movement, the accelerometer provides information about the movements to which it is subjected.

Figure 6 shows the accelerometer uses the displacement of a solid mass relative to its container to measure differences in acceleration. In Image A, the container is at rest and the mass remains centered between two bars; in this state the accelerometer outputs a constant intermediate voltage. If the container accelerates in the direction of the bar to the right (shown in Image B), the inertia of the mass causes it to lag 
behind, compressing the spring behind it and stretching the one ahead of it. As this is occurring, the device registers a higher voltage relative to the acceleration measured. Upon deceleration, the mass returns to its resting position and the output voltage correspondingly decreases.

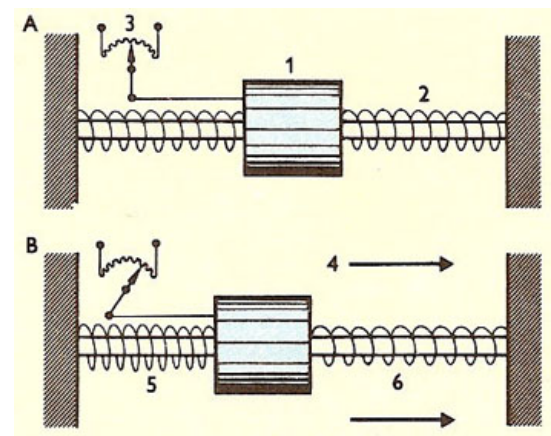

Figure 6. Basic electromechanical linear accelerometer (Source: IEEE GlobalSpec, 2016)

Accelerometers can be constructed in various forms using different technological means and can be used in a wide range of applications over a variety of industries such as (IEEE GlobalSpec, 2016):

i. $\quad$ Product testing (vehicle acceleration)

ii. Structure testing (buildings and bridges)

iii. Electronic devices (fitted to tablets and mobile phones to enable automatic shut down when dropped)

iv. Condition monitoring (vibration in pumps, compressors, fans, and other machinery)

v. Remote marine animal tracking

vi. Seismology systems

vii. Inertial navigation systems

viii. Gravimetry

An accelerometer is dividing into three types of device, namely:

a) Single-axis accelerometers are among the most common types. They are often used to measure simple vibration levels. An example of a single-axis device can be seen in the image under 'Construction and Operation' above.

b) Two-axis accelerometers are designed to measure acceleration or vibration along both an $\mathrm{x}$ - and $\mathrm{y}$-axis (simply "forward, backward, and side-to-side") - Figure 7.

c) Three-axis devices add a vertical z-axis to the two-axis accelerometer. These are capable of complex 3dimensional positioning and measurement. In lieu of a discrete three-axis accelerometer, a pair of two-axis accelerometers placed at right angles accomplishes the same effect - Figure 8.

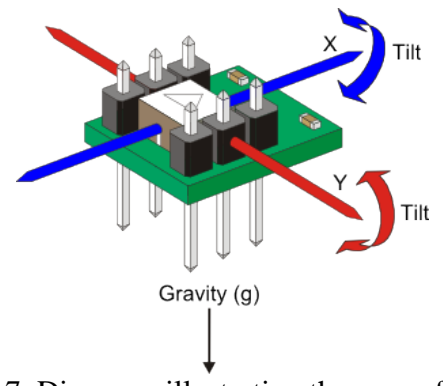

Figure 7. Diagrams illustrating the axes of 2-axis (Source: IEEE GlobalSpec, 2016)

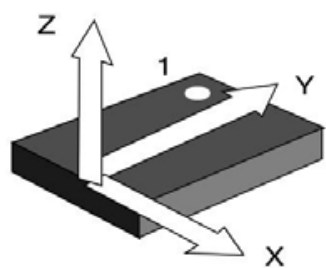

Figure 8. Diagrams illustrating the axes of 3-axis accelerometers (Source: IEEE GlobalSpec, 2016)

Nowadays, tiltmeters are widely used, often as part of measurement systems with an accuracy of about $0.01^{\circ}$ for the inclination is sufficient for many purposes (Woschitz \& Macheiner, 2007). Usually, a tiltmeter (Figure 9) is attached to the component and cannot be removed during its guiding process. According to Woschitz and Macheiner (2007), typical time spans for such a guiding process of a component are several hours up to a few weeks. Therefore, the long term performance, the zero point stability, the temperature dependence and the dynamic properties of a tiltmeter are of special interest.

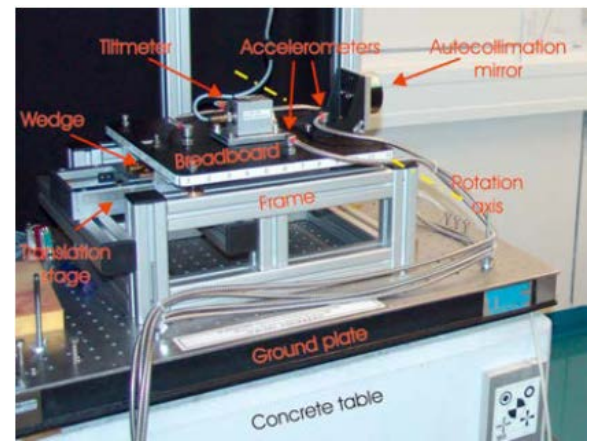

Figure 9. Kinematic test facility with attached tiltmeter and accelerometers. (Source: Woschitz and Macheiner, 2007)

\section{CONCLUSION}

The concrete structure displacement is related to the durability of submerged concrete structures. The concrete failure is also caused by the action of various chemical and physical agents. The main phenomenon leading to the durability submerged concrete are pressure resistant, concrete structures which related such as cracks, debonds, and delamination. To avoid the displacement of submerged concrete structure it is important to use a good quality concrete, with good impermeability and an adequate protective layer. One way to detect submerged concrete displacement is by using the geodetic surveying and geotechnical structural measurements techniques.

\section{ACKNOWLEDGEMENTS}

The author would like to acknowledge the support received from the Ministry of Higher Education, Universiti Teknologi Malaysian who has been directly involved, give their permission and support this study. This research work is part of University Research Grant (Cost Center No. Q.J130000.2527.13H04). 


\section{REFERENCES}

Avadutala, V. S. (2005). Dynamic Analysis of cracks in Composite Materials. Non Destructive Testing.

Barnes, J., Rizos, C., Kanli, M., Small, D., Voigt, G., Gambale, N., \& Lamance, J. (2004). Structural Deformation Monitoring Using Locata, (July 2004), 1-16.

Beshr, A. A. E. (2015). Structural Deformation Monitoring and Analysis of Highway Bridge Using Accurate Geodetic Techniques, (August), 488-498.

Bill Mosley, John Bungey and Ray Hulse (2012), Reinforced Concrete Design, Palgrave Macmillan, ISBN-13: 978-0230 30285-3.

Browning, J. (2011). Modeling Surface Deformations and Hinging Regions in Reinforced Concrete Bridge, (11).

Burchfield, T. R., \& Venkatesan, S. (2007). Accelerometer based human abnormal movement detection in wireless sensor networks. Proceedings of the 1st ACM SIGMOBILE International Workshop on Systems and Networking Support for Healthcare and Assisted Living Environments, 67-69. http://doi.org/10.1145/1248054.1248073

Campos, A., Lopez, M, Blanco,A, and Aguado, A. (2016). Structural diagnosis of a concrete dam with cracking and high non- recoverable displacements.

Ehigiator, M. O. (2013). Utilization of Kalman Filter Technique in Deformation Prediction of Above Surface Storage Tank, 21(1), 18-24.

Holland, R. B. (2012). Durability of Precast Prestressed Concrete Piles in Marine Environments, (August).

IEEE GlobalSpec (2016). Accelerometer. Received: 25 July 2016. Available at http://www.globalspec.com/learn more/sensors_transducers_detectors/acceleration_vibratio n_sensing/accelerometers.
Kwan, A. K. H., and Wong, H. H. C. (2011). Durability of Reinforced Concrete Structures , Theory vs Practice, 120.

Live, M., Southern, A., \& Lobster, R. (2001). Recommended Guidelines, 54-55.

Melorose, J., Perroy, R., and Careas, S. (2015). No Title No Title. Statewide Agricultural Land Use Baseline 2015, 1, 1-10. http://doi.org/10.1017/CBO9781107415324.004

Mohammed, T. U., Hamada, H., \& Yamaji, T. (2003). Marine Durability of 30-Year Old Concrete Made with Different Cements, 1(1), 63-75.

Naval Facilities Engineering Command (1995). Maintenance of Waterfront Facilities. Technical manual. NAVFAC-HO104. National Technical Information Service. Springfield.

Othman, Z. (2011). Landslide Monitoring Using Global Positioning System And Inclinometer Techniques. Doctor of Philosophy Thesis. Faculty of Geoinformation and Real Estate. Universiti Teknologi Malaysia.

Polder, R. B., and De Rooij, M. R. (2005). Durability of marine concrete structures - Field investigations and modelling. Heron, 50(3), 133-154.

Romer, M. (2013). Durability of Underground Concrete.

Song, H. (2005). Service Life Prediction of Cracked Reinforced Concrete Structures subjected to Chloride Attack and Carbonation. Workshop on Service Life of Conrete Structure.

Tada, H., Paris P. C., and Irwin, G. T., (2000), The Stress Analysis of Cracks Handbook, 3rd Ed., U.S.A.

Woschitz, H., \& Macheiner, K. (2007). Static and kinematic testing of tiltmeters : facilities and results. Vermessung \& Geoinformation, 2, 134-142. 